\title{
We Still Have Mutual Friends
}

\author{
Sierra Burrier ${ }^{1 *}$
}

\begin{abstract}
The project We Still Have Mutual Friends is a qualitative interview study into women's experiences with sexual violence. Through the interview process, mostly face-to-face recorded interviews, I have evaluated multiple facets of sexual abuse/marginalization and their consequences on survivors. In total, I interviewed thirty-two women about their familial background, their adolescence, and depending on their age, their life experiences with their sexuality. Some of the facets I have focused on are the disparity between a subject's definition and their experience of sexual assault. I have also evaluated their self-awareness of this disparity, and why they think it occurs. I tried as much as I could, to ask questions in an order/way that did not create preferential answering. Because these interviews followed a standard oral history format of open-ended questions with follow-ups based on the interviewee's answers, instances of leading answers were possible. Seventeen out of thirty-two women were white, with the next largest group being Hispanic, and then Black. With ages ranging from eighteen up to fifty-eight, several generational voices are accounted for. While there were certain trends found within types of assault, and who it was (trends not entirely new to us), one thing I discovered is a similar background every person shared with their family. All the women had at some point experienced some sort of "body policing." I hope this project has provided a more holistic view into the world of sexual violence that women face.
\end{abstract}

Keywords

Me Too Movement - Sexual Violence - Sexual Assault

${ }^{1}$ Integrative Sudies, University of North Texas

*Faculty Mentor: Dr. Clark Pomerleau

\section{Contents}

\section{Introduction}

1 Equipment and Methodology

1.1 Demographics . . . . . . . . . . . . . . . 2

2 Results

3 Conclusions

4 Their Stories

References

\section{Introduction}

Take any history class ever and there is a story about assault. Sometimes used as a form of war, sometimes brushed over in politics, religion, anecdotes well-kept; stories riddle our history of sexual assault. Until recently, for some, perhaps it always seemed they were so far away from us. To those who experience it, perhaps they were bleeps on the radar one ignores in passing as a personal history all their own. A story they do not tell. A story no one really wants to hear. A couple years ago I was exploring the ideas of female fear around men. Resentment for their actions, perhaps even their indirect actions. Exploring what anxieties separate us when we walk into a room, when we walk to our car. This was before the Me Too movement, the Time's Up movement, before the world largely rallied behind survivors telling their stories. When I would discuss this topic, it was a conversation killer of sorts; people did not want to hear about, did not want to discuss 1 it, and at times flat-out told me that the things I spoke of 1 were specific to only me. I knew so many women that had similar thoughts, experiences, feelings, and I knew that one of the ways I could show this was to give them a platform. So here it is, all thirty-two interviews. These women allowed me into their lives, stories, and heartache. They permitted me to ask incredibly personal, jarring, and explicit questions. The women who I interviewed gave incredibly thorough accounts, which is what allowed me to put together data and draw some patterns. Although there was much variation from experience to experience, there were patterns within familial backgrounds, the effects of assault, and who assailants were.

\section{Equipment and Methodology}

Throughout the project I used five pieces of equipment to conduct the research. I used two notebooks, one recorder, a laptop, and my car to get around. The interviewee would typically reach out to me from hearing about the project from me, or through someone else that had been interviewed, or was talking about it, or through the online Facebook page I created. Although most of these came to fruition, which I will discuss shortly, sometimes they did not. This research project is predicated on the importance of consent, so I never pushed for an interview. Those who were more enthusiastic, 
consistent, or persistent in the need/want to be interviewed were those I interviewed. This is important to note; while there are many women out there who have experienced various types of sexual violence, I interviewed only those that wished to speak on it and an amount manageable within my work schedule. This is not necessarily an indicator as to how often it occurs.

Though most of my interviews were in person, there were a few that were not. Out of a total of thirty-two interviews, there were five write-ins, one Skype interview, and two phone interviews. For the interviews that were write-ins, I sent interviewees one of two editions of Word documents. The first edition was used two times, and then revised for the second edition. At first it comprised thirty-five questions, and then the second edition was forty-seven questions. The revised version was not that much different, but the questions were mostly broken up into individual more pointed questions in order not to confuse the interviewee. The Skype interview was done with a person across the country, and the two phone calls were people in state but too far to interview in person. Overall, in person was the best method, then phone call (no break up in the dialogue like Skype), Skype, and then writeins. That said, using multiple communication methods was more inclusive. When doing in person interviews, although I had several general questions memorized to ask, I was able to delve more into their personal histories within certain aspects of their questions. For instance, when I would ask, "did your family discuss sexual assault?" and they would respond, "not exactly," I could ask them to elaborate or explain.

Although these were best, the two phone calls were also good at receiving data and the stories, but not seeing body language made it difficult to know comfort level without asking (which I did, but it's still best when you can see how a person is responding). This gave the Skype interview an advantage, but my interviewee via Skype was extremely comfortable and used to sharing her story, so that may have swayed why I put more weight on the sound issue (Skype cutting in and out for our voices if one person talked over the other). There were a few instances where one person would talk at the same time as the other would, and it would throw off the interview for a few seconds since the sound would cut out. Because of the nature of friendliness and ease of conversation, it did not seem to have a lasting effect on the interview. Doing interviews in person resulted in many unplanned questions, which to me for qualitative research, was so important. Sticking to very specific questions is great for raw data, but getting background into all the facets that go into sexual violence and ones' coping with it was important to me.

First in the interviews, I would start with background questions, like "did your family ever discuss the concept of consent," then work up to questions like, "were you ever sexually assaulted by a close family member and what occurred?" A lot of in person questions were diverse based on the person's experiences. Once the interviews were concluded, I would transcribe the interviews and ask for their permission to share certain quotes I sent back to them to check over. Generally, there was this shock rereading the things they had said. Not extreme, but a feeling of, "when you see it in writing, it is so much more harsh." Once something moves from a scenario with body language, tone, and even jokes between stories and background, you just get the facts. It becomes real, raw data that you see as everyone else will read it. It becomes somewhat two-dimensional. There is some power to reading it though, without hearing your own voice. It becomes a force for uniting with other women when you realize how similar your stories are, if not in exact detail, in the feeling the details could create. The interviews, while professional, were intensely personal. I did voice my bias against sexual violence, I voiced that I do not think they are to blame at all, and I relayed similar stories between people (still anonymously). I comforted many if not all the people I interviewed. In stories like these, where they may have never heard the words "it is not your fault," I thought it imperative for them to hear it from me. In that sense, these interviews methodologically fit into feminist ethnographic practice where the researcher prioritizes giving back to the individuals and community who generously give her their time and energy. Giving back in this case happened on the person-to-person level and with the choice of a platform for sharing findings that would be most accessible to participants.

\subsection{Demographics}

Demographics for my research were out of thirty-two mostly women/with some open to varied identification. Out of the thirty-two people, seventeen were white at 53\% (I have rounded all decimals up for this paper to whole numbers). Seven women were Hispanic, at $22 \%$, and two were mixed white and Hispanic at $6 \%$. Three women were Black at $9 \%$, and one woman was mixed Black/white at 3\%. There was one Asian identifying woman also at $3 \%$, and one international woman also at $3 \%$. My study mimics the U.S. census data on population relatively closely, but with slightly more diversity. But my study is small and therefore cannot be extrapolated as statistically significant; it is qualitative not quantitative. While various generations were accounted for, the majority of my interviews were within the eighteen to twenty-five age range, with twenty-one of my interviews falling into that category at $66 \%$. The other age ranges are twenty-five to thirty-five at $19 \%$, thirty-six to forty-five at $9 \%$. Both forty-six to fifty-five and fifty-six to sixty-five account for $3 \%$ each. Reasons for this sway in data are the ages of people with access to my project are likely younger, and the majority are within this college town (Denton).

\section{Results}

It is important to note that the women I interviewed were women who actively consented or even pursued being interviewed. There are countless more who do not wish to tell their story now, yet, or maybe ever. To frame the following paragraphs, I am going to define sexual assault and rape. Sexual 
assault and rape for the purpose of this project have overlapping definitions. Both are instances of sexual acts without the persons consent, mostly denoted through physical means, but can also be non-physical. The instances within this study, however, were all physical acts. Rape in general, has a heavier connotation, on terms of identifying ones' experience with the word. But for the purpose of this paper, I have combined rape and sexual assault under the same definition, since most interviews of late separated the terms mostly based on the feeling that rape constitutes.

RAINN via the Department of Justice (DOJ) estimates that in 2015 there were 1.6 sexual assaults/rapes per a thousand people in the U.S.[1] This was based on occurrences of assaults throughout the entire U.S., condensed down to $\mathrm{x}$ out of a thousand (whether these were reported, convictions, or estimates is not known). Feminists have estimated 1 in 5.[2] I know that this study of thirty-two women cannot show the inaccuracy of that number, but that number cannot be accurate by the standard of how I have defined sexual assault and the numbers I found. Out of the thirty-two women I interviewed, there had been at least sixty-five occurrences of sexual assault. While my definition may be different from that of the DOJ, I think what it shows is that there are so many assaults that go unreported. In the report it states that one in six women has been assaulted, while this number makes a bit more sense than the 1.6 per 1,000 estimate, there needs to be a fuller study on how many assaults go unreported. We can only have conjecture currently, but it seems the number is much higher than that.

Out of the sixty-five assaults that occurred, I have broken down the numbers on where they occurred. The two largest places being at the assailants' home, at $28 \%$, and the victims' home at $26 \%$. Nine occurred at school at $14 \%$, seven at work and at a party, $11 \%$. Six assaults occurred in public, accounting for $9 \%$. Three in a car or at a bar at $5 \%$, one in a hotel and one in a doctor's office at $2 \%$ each. It should be noted that some of these were "single incidents," and some of these were instances of ongoing abuse. In those instances though, I have condensed it for the purposes of this paper to the location it occurred. According to RAINN, $72 \%$ of assaults occur from someone the victim knows.[3] My research also mimicked this with $70-80 \%$ of assailants being someone the victim knew previously. Although all of these fell into the definition I have provided, not every person identified their experience as assault or rape. There were discrepancies at times between the experience and the defining of it.

People cope with sexual assault differently after it has occurred. Some experience very little PTSD afterwards, or triggering situations, and some it bothers night and day. One thing I found is survivors' discrepancy within defining their experiences. During the interviews I would ask a person to define harassment, sexual assault, and rape. Then after describing their experience, I would ask them to define their experience within these definitions. In fairness, there is a lot of gray between these words. Sometimes things happen and we can feel that it was wrong or not consensual, but we cannot articulate exactly why at the time. But, based on interviewees' own definition and then their defining of their experience, sometimes interviewees did not categorize experience that fit their definition as assault or rape. Some said that what had happened to them did "not feel impacting enough to be defined as rape (or sometimes assault, but usually rape)." But there was a theme, before the Me Too movement began in particular, for this discrepancy to stem from discomfort. They did not want to be someone who had been raped. At the end of the day, these are their stories to tell, and they get to choose how to tell them. I told them I was documenting these discrepancies, but regardless, it is still what the survivor wishes to define it as.

Some effects of assault were increased or decreased sexuality. Some people, whilst experiencing an increase in sexual pursuits, did not necessarily enjoy these pursuits. There were a few people who felt after their assault, more sexualized in general. One woman in particular confided to me that after her assault she quit saying no to sexual propositions. She said as long as she was saying yes, she was in control. But she also acknowledged that she did not always want to say yes, and also that there were certain men she believed would not have cared if she said no. Saying yes can be a coping mechanism within sexual assault.

An important thing to note is that a yes, under duress, pressure, coercion, guilt, and other forms of toxicity, is not consent. Saying yes, within my interviews, was seen as a way to hold onto some semblance of control. In a way it works, and it makes sense. If you say yes, things are less likely to be "as violent." It's all abuse, but if you say yes, at least parts of you will survive.

While doing this project, and looking for trends, there was an overwhelming amount of variation between experiences. But one thing stayed in common with every single person I interviewed. Body policing. It's not a term you see in scholarly articles typically, it's in the Washington Post, Huff Post, sites like everydayfeminism, and even urban dictionary. Yet every single woman has experienced some form of it, typically beginning as a child.

The idea that we can teach women to wear longer skirts, not show too much cleavage, not show their bra straps, not wear certain kinds of jewelry, not dye their hair a certain way, not dress a certain way, and they will be safer is unequivocally flawed. We know through studies, and even in this project, the vast majority of assaults are from people we know. They are not random people that our society says women (and men) have "tempted." They are our fathers, uncles, boyfriends, dates, and teachers. But even if women had been wearing mini-skirts, or a black bra in a white shirt, why do the victims of this crime get the focus of the assault? The blame? Do we deem men/assailants so animalistic that even the idea they are at fault for these behaviors is so foreign to us, we resort to the tried-and-failed idea that women are to blame for these things not within their control? It seems to 
me we think that body policing women makes them safer. It makes us as a society feel as if we can point to this pattern of action/behavior/dress and say "that's what caused it." It makes everything seem less chaotic. But it is not. Often, I have heard, before, and through this study, that we police women because we can't control their assailants. But this is plain fallacy, since we know most of the time it is people they know, these are not solely random acts of violence. We know throughout studies, exhibits, and accounts, that nothing a woman wears, or doesn't, causes assault. Assailants cause assault, combined with the societal failings to educate against nonconsenting behaviors, and the general failure of patriarchal/male pleasure-based societies. Add in the lazy idea that people with inherently violent/malicious personality traits cannot be helped. The result of these words, behaviors, body-policing women, has caused an immense number of victims blaming themselves.

Victim blaming does not happen in a vacuum. While one reason for it is the way women are raised from their youth to see themselves as sexual temptresses responsible for the 'indiscretions' (all the way up to violence) of men, another is the way we teach about "stranger danger. "One thing many people had in common is the idea that you "don't let strangers do things to you." While some families focused on the "if this happens, tell us," others focused on, "don't let this happen." This may not seem incredibly harmful at a young age, but as you get older the dialogue within yourself turns to: why did I let this happen? What could I have done differently? How did I provoke them? We learn that as adults we are held accountable for our actions, and what was shame as child (molestation), transforms into this other sinister thing: blaming oneself. Though victims are not accountable for these things and are not to blame for other people's sexual violence. But until very recently, that was not the conversation our culture was having. We teach children, then young adults, then older adults, that if they are "tricked" into trusting someone, they are naïve. Women are supposed to always straddle this line of not seeing every man as a possible assailant, because that's sexist, and at the same time, not trust a single person for fear of being told "you were stupid."

\section{Conclusions}

One thing I want to reiterate is that I think none of this data is to change the behavior of the victims/survivors. A qualitative study like this points to correlations and patterns rather than the whole picture. Nonetheless, others need these findings to learn what women have experienced, how to treat people better, and the importance of valuing consent. Centering on consent teaches that coercion is assault, that pressuring into sex is not ok, and that rape can occur within relationships and marriage. We are taught from a young age as women ${ }^{1}$ that our bodies are not our own through family, through our teachers, through over zealous dress code enforcers, through

${ }^{1}$ Interviews were all women; I cannot speak to male experience. movies, media, talk-show hosts, etc. We live in a world now that knows the Me Too movement, the Time's Up movement, the ousting of men from public arenas where they are threats to those under them. We are hearing more and more voices in unison with the idea that: "women shouldn't have to be dressed modestly to be respected."

Let's all turn the table around and evaluate the source of the behaviors of assailants. Because we know that people are not incapable of self-control. Sometimes assault is something someone decides to do in an instant. Sometimes assault is something someone decides to do the first time they meet someone. Sometimes assault is your husband angry that you say no to him one night. We need to ask ourselves what we are doing as a culture, what we have been doing, to not have this conversation with the people committing these acts. The change does not start from the victims of these acts, and nor should it. We can oust men and women from the heads of various organizations, careers, public arenas, and yes, we helped people from those abusing their power. But how we do we create a world where abusive people do not get those positions in the first place? All in all, my data is from a limited number of people, so its representation to a larger community is minimal. There are some correlations, and loose trends that can be drawn. Lastly, as stated earlier, these are the interviews of women that wanted to speak to their experiences. There are many more that haven't, don't, and can't. Many choke on the name of their assailant. If this project created anything, hopefully it is a community where these stories are welcome whenever the survivor is ready.

\section{Their Stories}

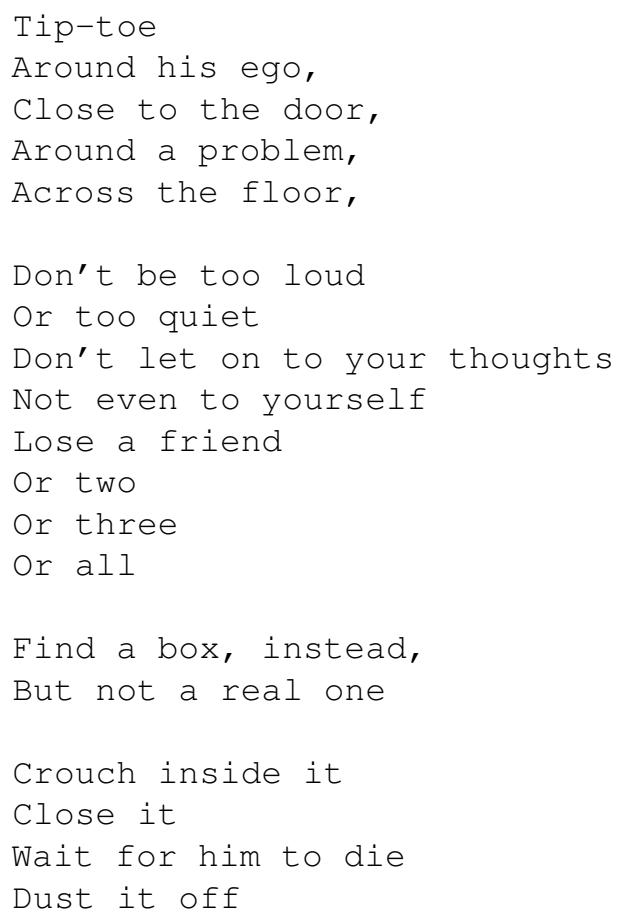




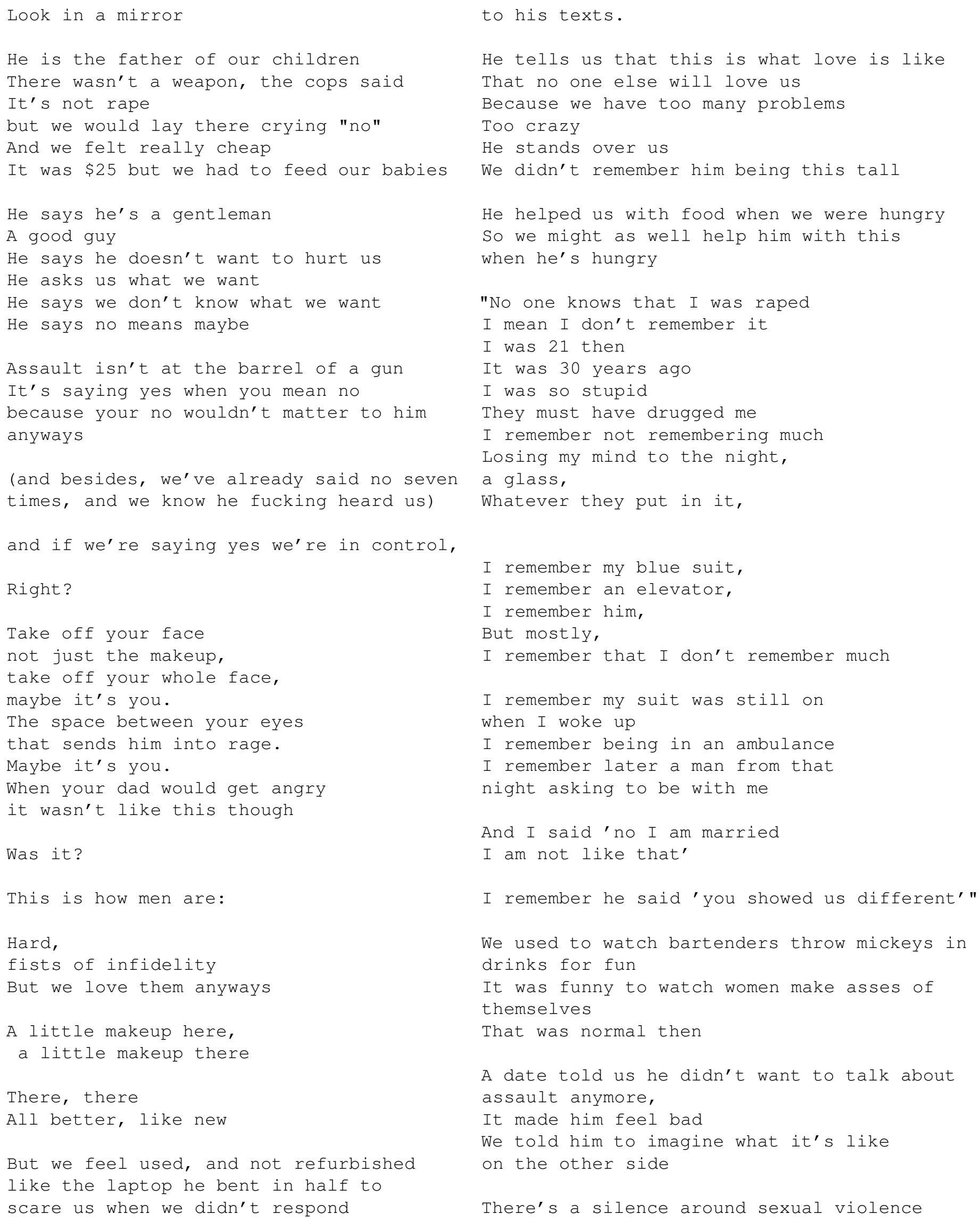




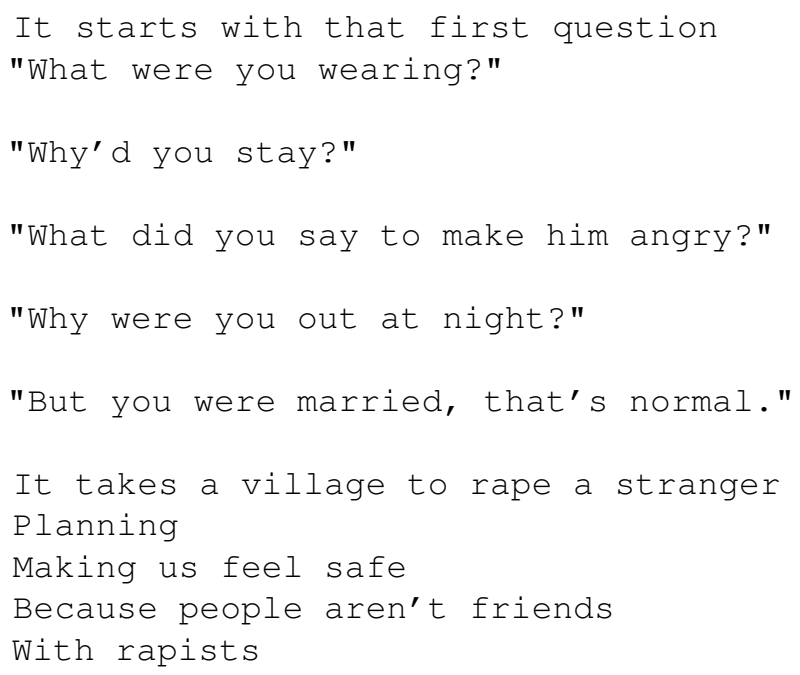

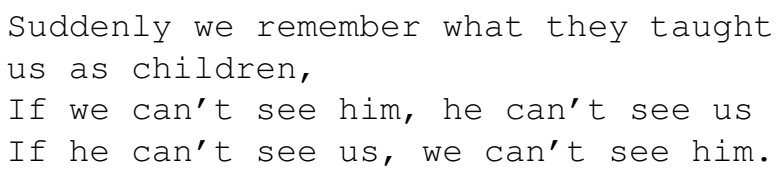

\section{References}

[1] Department of Justice. Scope of the problem: Statistics. https://rainn.org/statistics/ scope-problem. Accessed: 2018-04-02.

[2] National Organization for Women. Violence against women in the united states: Statistics. https://now. org/resource/violence-against-women. Accessed: 2018-04-03.

[3] Department of Justice. Perpetrators of sexual violence. https://https://rainn.org/statistics/ perpetrators-sexual-violence. Accessed: 2018-04-02. 